\title{
Primary localised amyloidosis of the orbit
}

\author{
I E Murdoch, T J Sullivan, I Moseley, P N Hawkins, M B Pepys, S Y Tan, A Garner, \\ J E Wright
}

\begin{abstract}
Aims/background-Primary localised amyloidosis is rarely encountered in the orbit. The typical clinical and radiological appearances have not been clearly established, in particular the single site deposition of amyloid has never been proved. Methods-Six cases were reviewed in detail and their clinical and radiological characteristics are described here. Four patients had scintigraphy with ${ }^{123}$ I serum amyloid $P$ component and one patient had typing of the amyloid fibrils.

Results-All the patients had a firm mass in the upper orbit with a predilection for the region of the lacrimal gland. Computed tomography showed a homogeneous mass with thickening and irregularity of the adjacent bone and/or calcification within the mass. None was associated with systemic disease. Scintigraphy with ${ }^{123}$ I serum amyloid $P$ component demonstrated that the amyloid was confined to the orbit. In one patient the amyloid fibrils were derived from an IgG4 heavy chain constant domain. The lesions were partially excised with subsequent clinical stability over 6 months to 18 years in all but one patient who had continued enlargement of the lesion.

Conclusion-There is a characteristic clinical and radiological pattern for primary localised amyloidosis of the orbit. The disease process is truly local and not part of a systemic process. A majority respond to simple debulking with subsequent observation.

(Br F Ophthalmol 1996;80:1083-1086)
\end{abstract}

Orbital Clinic, Hospital, London

I E Murdoch

T J Sullivan

I Moseley

J E Wright

Immunological Medicine Unit, Hammersmith Hospital, London P N Hawkins M B Pepys S Y Tan

Institute of Ophthalmology, London

A Garner

Correspondence to: I Murdoch, Moorfields Eye Hospital, London ECIV 2PD

Accepted for publication 16 September 1996

Amyloidosis is a disorder of protein metabolism characterised by the extracellular deposition of abnormal protein fibrils. ${ }^{2}$ It may be localised or distributed throughout the body, causing organ damage and serious morbidity. Major visceral involvement, especially of the kidneys and heart, is usually fatal. The fibrils derived from a variety of precursor proteins in different forms of the disease but are always intimately associated with sulphated glycosaminoglycans. In addition, the normal circulating glycoprotein, serum amyloid $\mathbf{P}$ component (SAP), specifically binds to the fibrils and is a universal constituent of amyloid deposits.

Amyloid in the orbit is rare; there are only 27 previously reported cases. It usually occurs in isolation, not as part of a systemic disease. Previous reports have usually been limited to single case histories and the overall clinical pattern of presentation and radiology has not been well documented. Localisation of amyloid just to the orbit has usually not been established and apart from one of the cases in the present study ${ }^{3}$ the fibril protein has been identified only once before.

\section{Methods}

Six cases of primary localised amyloidosis were reviewed in detail.

\section{CASE 1}

A 60-year-old man noticed a slowly progressive drooping of the right upper lid for 12 years and double vision when looking down for 4 months. He was fit and healthy with no previous illness. There was a right ptosis of 2 $\mathrm{mm}$. The right eye was proptosed $4 \mathrm{~mm}$ and displaced downwards $10 \mathrm{~mm}$. There was no other significant ocular abnormality.

Plain films of the orbits were normal. Computed tomography $(\mathrm{CT})$ revealed a $2 \times 2 \mathrm{~cm}$ soft tissue mass, slightly denser than the brain, in the upper portion of the right orbit. The lesion was rounded, but more irregular superiorly, moulded to the globe, which it displaced anteroinferiorly, and extended forwards into the upper lid. There was questionable irregularity of the adjacent bone of the roof of the orbit, with possibly a small spicule of calcific density related to it. The paranasal sinuses showed evidence of widespread inflammatory disease.

The lesion was approached trans-septally and the major portion of the mass excised. Histology showed a hypocellular mass of fibrous tissue and amyloid. The amyloid had a predominantly perivascular location. A small number of lymphoid cells were also present. Scintigraphy with ${ }^{123}$ I SAP was performed. There has been no recurrence during a follow up of 6 years. which form the bulk of amyloid deposits are
CASE 2

An 87-year-old man with mild bronchitis and an 8 year history of non-insulin dependent diabetes mellitus noticed a painless progressive swelling of his left upper lid for 6 months. The left eye was displaced medially $3 \mathrm{~mm}$ by a firm subcutaneous mass in the upper lid which extended subconjunctivally over the lateral part of the globe. The palpebral aperture was narrowed by $6 \mathrm{~mm}$ and there was restriction of vertical and horizontal movement of the globe. Ocular examination was otherwise normal.

CT showed a $2 \times 1 \mathrm{~cm}$ homogeneous soft tissue mass in the region of the left lacrimal gland, whose density was slightly higher than that of the brain. The mass appeared to involve the anterior end of the lateral rectus muscle. There was generalised sinusitis. 


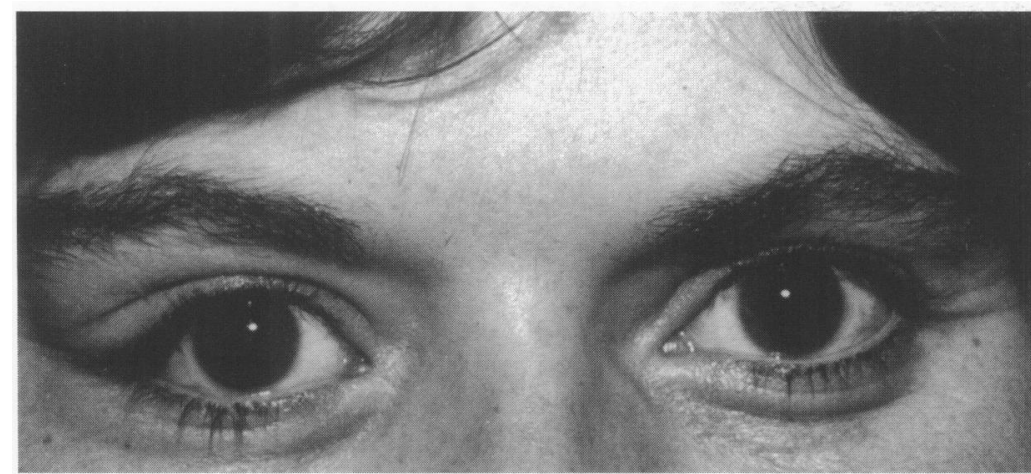

Figure 1 Primary localised amyloidosis of the orbit, case 3, showing mass in right upper eyelid.

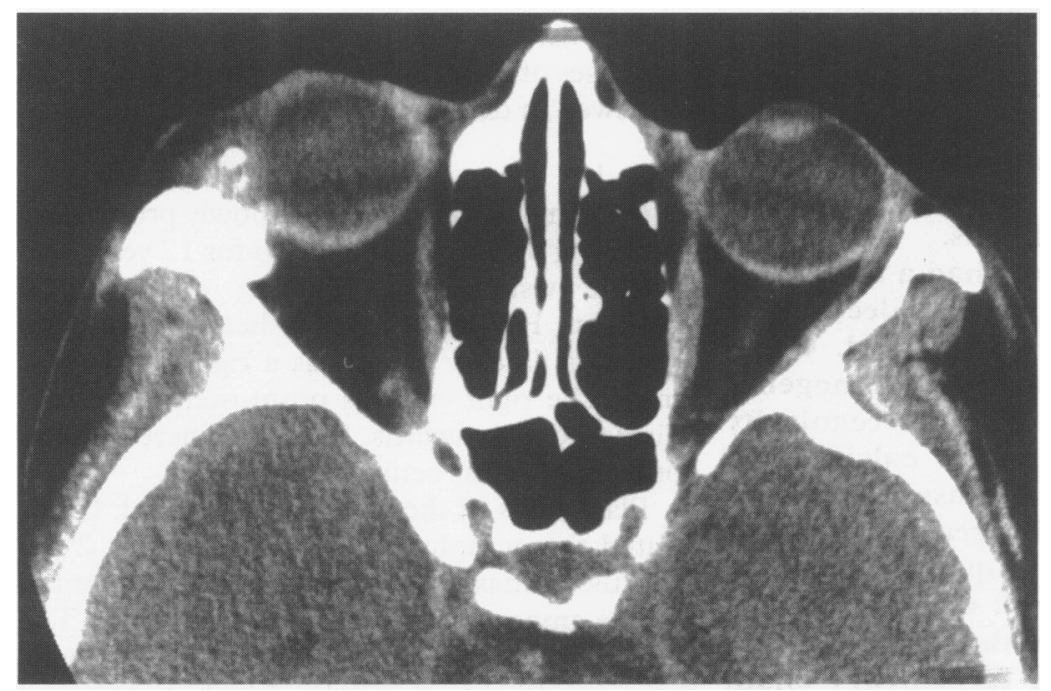

Figure 2 Primary localised amyloidosis of the orbit, CT scan of case 3 showing ocular displacement by mass, calcification within mass, and thickening of the lateral wall of the orbit.

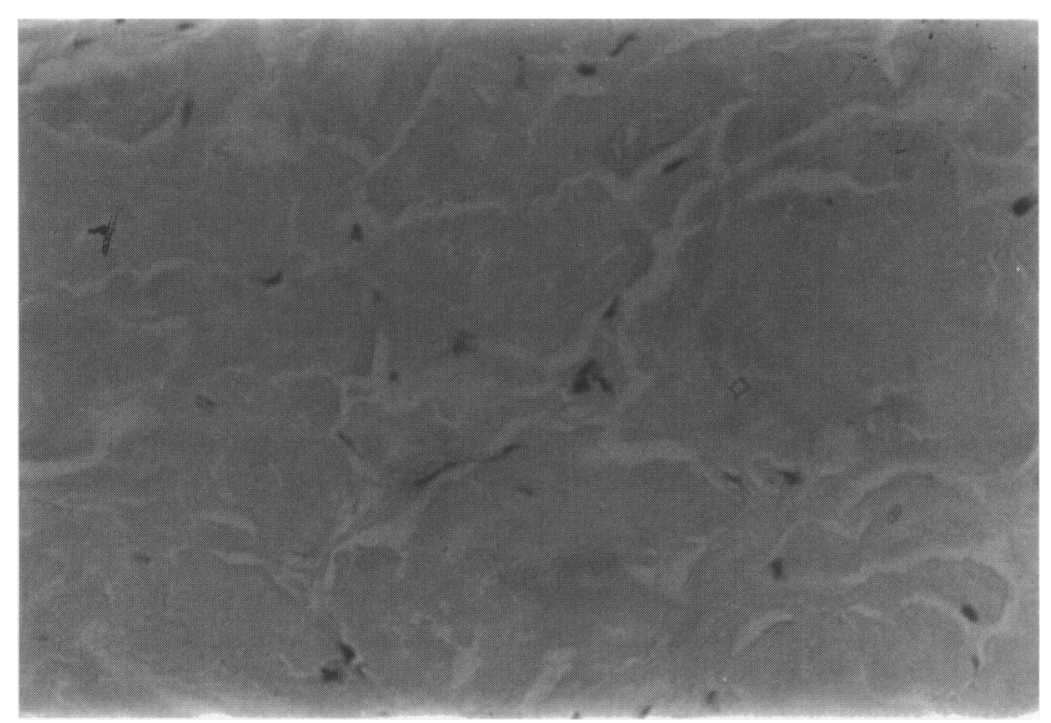

Figure 3 Primary localised amyloidosis of the orbit, showing the extensive amorphous material typical of amyloid in case 3.

Biopsy of the mass revealed dense interstitial and vascular wall amyloid, with small chronic inflammatory cell aggregates. Follow up is limited to the immediate postoperative period.

CASE 3

A 29-year-old woman with no history of previous illness had a 4 year history of recurrent periorbital bruising and a lump in the lateral part of her right upper eyelid (Fig 1). She experienced periocular discomfort once or twice a week, aggravated by vomiting or straining. There was a firm fixed mass of $2 \mathrm{~cm}$ by 1 $\mathrm{cm}$ attached to bone at the right lateral canthus with a palpable irregularity of the adjacent bone. The right eye was proptosed $1 \mathrm{~mm}$ and displaced $4 \mathrm{~mm}$ medially. There was no other ocular abnormality.

CT showed a mass in the right lacrimal fossa, $1 \mathrm{~cm}$ in transverse and $2 \mathrm{~cm}$ in anteroposterior diameter. The lower part of the lesion was of soft tissue density, slightly denser than the brain, but its upper part was densely calcified, resembling a lobulated nodule of bone (Fig 2), with a less dense centre. The anterior portion of the lateral rectus muscle may have been involved by the mass, which was moulded to the globe, displacing it downwards and forwards. An apparent plane of cleavage was visible between the calcified or ossified component and the lateral wall of the orbit, but the latter was thickened and there was also a small fleck of calcification near its outer surface, in the temporal fossa. CT 15 months later showed some progression of the mass, particularly the calcified or ossified portion.

Two orbital biopsies were taken 12 months apart. The amyloid tissue was exposed and further dissection showed that the superotemporal orbital wall was soft and red. Biopsies taken from this area and from the amorphous material in the lacrimal fossa contained abundant amyloid (Fig 3). The bone around the amyloid was decalcified and showed formation of woven bone and remodelling of lamellar bone with osteoclastic activity. There was variable recalcification. Scintigraphy with ${ }^{123}$ I SAP was performed. The lesion has remained static over a further 4 years of follow up.

CASE 4

A 42-year-old woman had noticed a swelling in the inner aspect of her left upper lid for 18 months. There were no past illnesses. The left eye was displaced $4 \mathrm{~mm}$ laterally and $2 \mathrm{~mm}$ inferiorly by a firm mass deep to the medial upper lid, measuring $4 \times 1 \mathrm{~cm}$. This mass could be seen in the upper fornix as an area of grey tissue beneath the conjunctiva. There was no other ocular or orbital abnormality.

CT demonstrated a somewhat inhomogeneous soft tissue mass, slightly denser than the brain, in the superior temporal quadrant of the right orbit. It measured $2.5 \mathrm{~cm}$ in anteroposterior diameter, $2 \mathrm{~cm}$ across, and was $1 \mathrm{~cm}$ thick. The mass was rounded, moulded to the globe (Fig 4), and appeared to involve the superior rectus muscle. The overlying bone was thickened with a focal zone of irregular calcification or ossification posteriorly either on the undersurface of the bone or separate from it. There was generalised sinusitis.

The lesion was biopsied and showed extensive amorphous material staining positively for amyloid with occasional blood vessels and some mild chronic inflammatory cell infiltration. Scintigraphy with ${ }^{123}$ I SAP was performed. Over 3 years of follow up the mass has slowly enlarged. As vision is not threatened it has been decided that the risks of surgical 


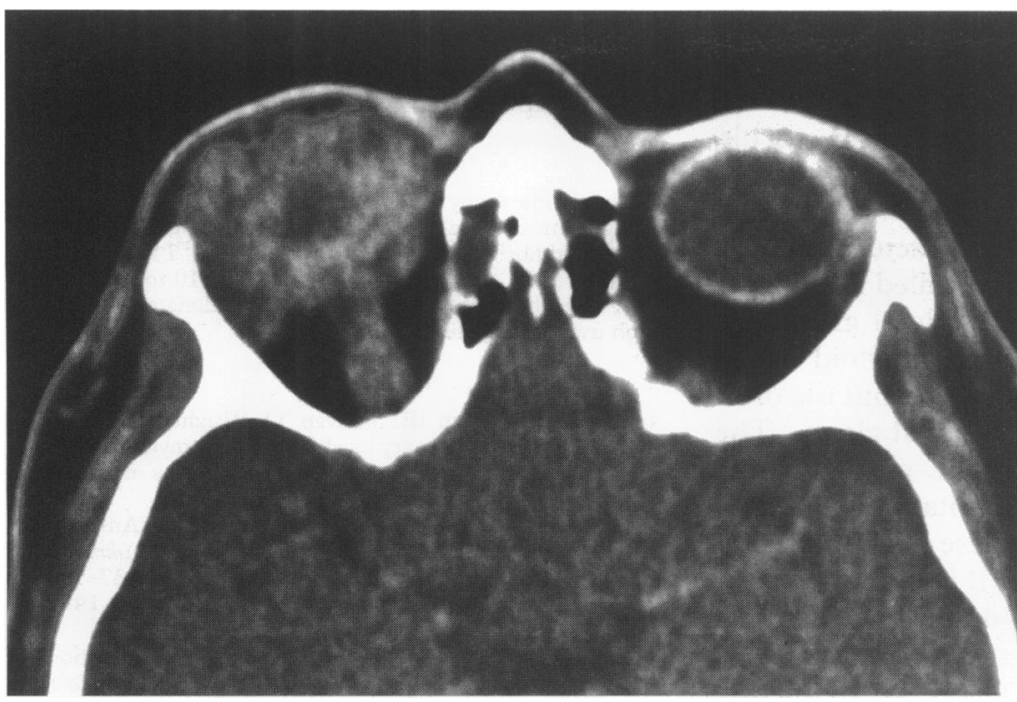

Figure 4 Primary localised amyloidosis of the orbit, non-homogeneous orbital tissue mass lateral to and above right eye, case 4.

intervention outweigh the benefits, so a conservative approach has been adopted.

CASE 5

A 67-year-old man noticed drooping and swelling of his left upper lid for 7 months. There was a firm subcutaneous, mobile mass superotemporally in his left orbit with no proptosis or displacement of the globe. His left palpebral aperture was narrowed by $2 \mathrm{~mm}$. No other ocular or orbital abnormality was found.

CT showed generalised but predominantly anterior, smooth expansion of the left lacrimal gland, which was of slightly higher density than the brain. The gland was moulded to the globe, which was displaced downwards and forwards. The adjacent bone appeared normal.

The lesion was biopsied and found to be within the lacrimal gland. Histology showed amyloid interspersed with blood vessels and mild chronic inflammatory cell infiltration. Over the subsequent 6 months there has been no progression of the lesion.

CASE 6

A 75-year-old woman, blind in her left eye from childhood trauma, noticed drooping of her right upper eyelid for approximately 1 year. She had no history of any systemic illness. Her acuity was $6 / 9$ and colour vision was normal. There was right periorbital oedema with $6 \mathrm{~mm}$ proptosis, $6 \mathrm{~mm}$ medial and $3 \mathrm{~mm}$ inferior deviation of the globe. The right eye could not abduct and all other movements were severely restricted.

CT showed a mass, generally smooth and lobulated, in the superior temporal quadrant of the right orbit. It was $3 \mathrm{~cm}$ in anteroposterior diameter, $2.5 \mathrm{~cm}$ across, and $2 \mathrm{~cm}$ vertically. The mass could not be separated radiologically from the lateral rectus muscle, and the superior rectus was also swollen. It was moulded to the globe, which it displaced downwards and forwards. The overlying bone was thinned. A small focus of calcification, resembling a phlebolith, was seen within the lateral part of the mass, adjacent to but separate from the bone of the lateral wall of the orbit.
Biopsy showed amyloid within the lacrimal gland, particularly around vessels, and a chronic inflammatory cell infiltrate. Whole body scintigraphy with ${ }^{123}$ I SAP was performed. Amyloid fibrils were isolated from resected tissue and the subunit protein was characterised by amino acid sequencing. There has been no progression of the lesion over 2 years of subsequent review.

\section{Results}

The most common presenting symptoms of primary localised orbital amyloid are ptosis, proptosis, and global displacement with no visual impairment. The lesion is typically a firm, non-tender, easily palpable mass in the superotemporal aspect of the orbit. In five cases the lacrimal gland was intimately involved with the amyloid mass.

CT scanning is the most helpful method of imaging. It typically shows a soft tissue mass in the superotemporal quadrant of the orbit, often centimetres in diameter and extending forwards to involve the upper lid. It is usually rather homogeneous, slightly denser than brain, and may show homogeneous contrast enhancement. Associated thickening and irregularity of adjacent bone and/or calcification within the soft tissue mass are changes suggestive of the diagnosis.

In no case was the biopsy proved orbital amyloid found to be part of a systemic disease. Scintography in cases $1,3,4$, and 6 proved the lesion to be unique to the orbit. Amino acid sequencing of the protein chain in the amyloid fibrils of case 6 showed it to be a constant domain of the heavy chain of IgG4. ${ }^{3}$

\section{Discussion}

Amyloid $\mathrm{P}$ component (AP) is a universal constituent of amyloid deposits and is derived from the normal circulating plasma protein, serum amyloid $\mathbf{P}$ component. Isolated pure human SAP radiolabelled with ${ }^{123} \mathrm{I}$ has been developed as a highly specific, sensitive, quantitative diagnostic tracer for all types of amyloidosis. ${ }^{45}$ It was used in four of our patients to demonstrate that the amyloid was confined to the orbit. Although SAP scintigraphy cannot exclude microscopic amyloid deposits elsewhere the negative results were in accord with the absence of any demonstrable visceral or other organ dysfunction.

Conlon et al in 1991 reported that the amyloid deposits in a 72-year-old woman who presented with bilateral lacrimal gland swelling showed immunohistochemical and immunoelectron microscopic staining for immunoglobulin $\lambda$ light chains. ${ }^{6}$ Case 6 in this series is the first case of localised orbital amyloidosis in which amyloid fibrils have been extracted, allowing direct chemical identification of the fibril protein in this individual as the third constant domain of $\gamma$ heavy chains of IgG4 subclass. ${ }^{3}$ While amyloid derived from Ig heavy chains is extremely rare, this being only the third reported example, monoclonal Ig light chains are very commonly the cause of both systemic and localised forms of amyloidosis. In all such cases there is an underlying clonal 
disorder of cells of B lymphocyte lineage, leading to monoclonal gammopathy that may be overt, as in multiple myeloma or so called benign monoclonal gammopathy, or occult, presenting only with amyloid. All forms of extracerebral solitary amyloid mass lesions that have been biochemically characterised have been of this Ig light chain, so called AL type.

In five of our cases the lacrimal gland was intimately involved with the amyloid mass. There are no lymphatic vessels within the orbit with the exception of the lacrimal gland. ${ }^{7}$ The predilection for the lacrimal gland in the majority of patients with orbital amyloid may be due to the presence of these lymphatics and is compatible with a clonal B lymphocyte basis for this condition. All of our cases remained unilateral in contrast with systemic amyloidosis in which the lacrimal gland is frequently involved bilaterally.

Twenty seven cases of orbital amyloid have been reported previously. Three of these were possibly secondary to infection ${ }^{8}$ or systemic disease. ${ }^{910}$ The remaining 24 cases $^{6}{ }^{11-32}$ show a very similar patern of presentation to our present series. The reported cases also find the three most common presenting symptoms to be ptosis, proptosis, and global displacement, with visual impairment due to the lesion being recorded only three times. ${ }^{11-13}$ The amyloid deposit is characteristically unilateral (19 reported cases) and confined to the upper part of the orbit (18 reported cases). Most (15) were described as hard or firm, fairly easily palpable and not tender. In one of our cases and in five other cases ${ }^{8111617}$ the mass was noted to be fixed to bone. Two further reports record a fixed mass. ${ }^{14} 15$

Comprehensive radiological reports of primary amyloid masses in the orbits are rare. Moseley and Sanders reported a patient with a large mass in the upper part of the right orbit which was radiologically inseparable from the lateral and superior rectus muscles. There was no other abnormality on the films and the mass increased in size over an 8 month period of radiological observation. ${ }^{21}$ In four of our cases there was some involvement of the rectus muscles, an observation made three times before. ${ }^{232526}$ These radiological findings are nonspecific but in four of our cases and a further four reported cases ${ }^{1122-24}$ associated thickening and irregularity of the adjacent bone and/or zones of calcification or ossification within the soft tissue mass were apparent. These changes are much more suggestive of the diagnosis.

Only one case report exists of magnetic resonance imaging in this condition. ${ }^{27} \mathrm{~A}$ proton density axial section showed a lesion of non-specific soft tissue intensity in an unusual position, below and abutting the optic nerve, which the authors mistook for a meningioma. Since calcification is helpful in differentiating amyloid from other lesions MRI is less suited than CT for imaging orbital amyloid.

The management of orbital amyloidosis is difficult. Most lesions slowly enlarge and cause problems by displacing the globe. Total excision is usually impossible and surgery should be directed to the excision of the major portion of the mass with the preservation of the palpebral lobe of the lacrimal gland, the lebator palpabrae superioris, and the rectus muscles.

We thank the many other ophthalmologists involved in the management of these patients for their help. Characterisation of the amyloid fibril protein and studies of with ${ }^{123}$ I SAP were supported by MRC Programme Grant G7900510 to MBP. Mr G Rose, consultant ophthalmologist, kindly donated the photograph used for Figure 1.

1 Tan SY, Murdoch IE, Sullivan TJ, Wright JE, Truong O, Hsuan J, et al. Primary localized orbital amyloidosis due to
deposition of the immunoglobulin gamma heavy chain CH3 domain. Clin Sci 1994;87:487-91.

2 Pepys MB. Amyloidosis. In: Frank MM, Austen KF, Claman HN, Unanue ER, eds. Samter's immunologic diseases. Fifth ed. Boston: Little, Brown, 1994:637-55.

3 Tan SY, Pepys MB. Amyloidosis. Histopathology 1994;25: 403-14.

4 Hawkins PN, Lavender JP, Pepys MB. Evaluation of systemic amyloidosis by scintigraphy with ${ }^{123}$ I-labeled serum amyloid P component. N Engl f Med 1990;323:50813.

5 Hawkins PN. Studies with radiolabelled serum amyloid P component provide evidence for turnover and regression of amyloid deposits in vivo. Clin Sci 1994;87:289-95.

6 Conlon MR, Chapman WB, Burt WL, Larocque BJ, Hearn SA. Primary localized amyloidosis of the lacrimal glands Ophthalmology 1991;98:1556-9.

7 Sherman A, Gonnering R, Dortzbach R. Identification of orbital lymphatics: enzyme histochemical, light microscopic and electron microscopic studies. Ophthalmic Plastic Reconstruct Surg 1993;9:153-69.

8 Handousa A. Localized intraorbital amyloid disease. $\mathrm{Br} \mathcal{F}$ Ophthamol 1954;38:510-1.

9 Howard GM. Amyloid tumours of the orbit. $\mathrm{Br} f$ Ophthalmol 1966;50:421-5.

10 Coats G. Disease of the sclera. Trans Ophthalmol Soc UK 1915;35:257.

11 Nehen JH. Primary localized orbital amyloidosis. Acta Ophthalmol 1979;57:287-95.

12 Raab EL. Intraorbital amyloid. Br $\mathcal{F}$ Ophthalmol 1970;54 445-9.

13 Imaizumi K. Ein noch nicht beschriebener Fall von primarer Amyloidentartung der Tränen und Speicheldrußen unter dem Bild er Mikuliczschen Krankenheit. Tohoku f Exp Med 1942;44:381-95.

14 Pollems W. Uber tumorformige lokale Amyloidosis in der Orbita. Graefes Arch Ophthalmol 1920;101:346-59.

15 Knowles DM, Jacobiec FA, Rosen M, Howard G Amyloidosis of the orbit and adnexae. Surv Ophthalmo 1975;19:367-84.

16 Kassman T, Sundmark E. Orbital pseudo-tumours with amyloid. Acta Ophthalmol (Copen) 1967;45:220-8.

17 Cohen MM, Lessell S. Amyloid tumour of the orbit. Neuroradiology 1979;18:157-9.

18 Go K. Uber einen Fall von Hyalin- und Amyloiddegeneration der Tränendruse. $Z$ Ophthalmol 1935;34:438.

19 Radnot M, Lapis K, Feher J. Amyloid tumour in the lacrymal gland. Ann Ophthalmol 1971;3:727-42.

20 Easton JA, Smith TH. Non-specific granuloma of orbit ('orbital pseudotumour'). F Path Bact 1961;82:345-54.

21 Moseley IF, Sanders MD. Computerized tomography in neuroophthalmology. London: Chapman and Hall, 1982:44-5.

22 Motta AO, Han JS, Levine M, Benson JE. Primary amyloid tumour of the lacrimal gland: CT findings. 7 Comput Assist Tomogr 1983; 7:1079-80.

23 Gean-Martin AD, Kirsch CFE, Vezina LG, Weber AL. Focal amyloidosis of the head and neck: evaluation with CT and MR imaging. Radiology 1991;181:521-5.

24 Levine MR, Buckman G. Primary localized orbital amy loidosis. Ann Ophthalmol 1986;18:165-7.

25 Liesegang TJ. Amyloid infiltration of the levator palpebrae superioris muscle: case report. Ann Ophthalmol 1983;15: 610-3.

26 Holmstrom GE, Nyman KG. Primary orbital amyloidosis localised to an extraocular muscle. $\mathrm{Br} f$ Ophthalmol 1987;71:32-3.

27 Lawton AW, Leone CR, Hunter DM. Optic nerve pseudomeningioma secondary to localized amyloidosis. Ophthalmic Plastic Reconstruct Surg 1989;5:52-5.

28 Groniowski J, Bernardczykowa A, Norn MS. Orbital amyloidosis. Acta Ophthalmol (Copen) 1965;43:725--9.

29 Schubert E. Amyloid tumor der Orbita. Klin Monatsb Augenheilkd 1972;160:467-8.

30 Richlin JL, Kuwabara T. Amyloid disease of the eyelid and conjunctiva. Arch Ophthalmol 1962;67:138-42.

31 Kaiser-Kupfer MI, McAdam KPWJ, Kuwabara T. Localized amyloidosis of the orbit and upper respiratory tract. Am $\mathcal{f}$ Ophthalmol 1977;84:721-8.

32 Savino PJ, Schatz NJ, Rodriques MM. Orbital amyloidosis. Can $\mathcal{F}$ Ophthalmol 1976;11:252-5.

33 Jensen OA. Bilateral amyloidosis of the orbit. Ophthalmologica 1976;173:70-8. 